\title{
Measuring Use and Creation of Open Educational Resources in Higher Education
}

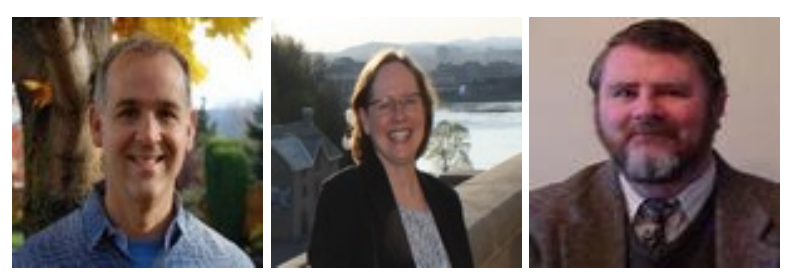

Ross McKerlich ${ }^{1}$, Cindy Ives ${ }^{2}$, and Rory McGreal ${ }^{2}$ ${ }^{1}$ Okanagan College, Canada, ${ }^{2}$ Athabasca University, Canada

\section{Abstract}

The open educational resources initiative has been underway for over a decade now and higher education institutions are slowly adopting open educational resources (OER). The use and creation of OER are important aspects of adoption and both are needed for the benefits of OER to be fully realized. Based on the results of a survey developed to measure the readiness of faculty and staff to adopt OER, this paper focuses on the measurement of OER use and creation, and identifies factors to increase both. The survey was administered in September 2012 to faculty and staff of Athabasca University, Canada's open university. The results offer a snapshot of OER use and creation at one university. The survey tool could provide a mechanism to compare and contrast OER adoption with other higher education institutions. Forty-three percent of those in the sample are using OER and 31\% are creating OER. This ratio of use to creation is introduced as a possible metric to measure adoption.

Keywords: Open educational resources; OER; open textbooks; open learning 


\section{Introduction}

Open educational resources (OER) can be defined as "materials used to support education that may be freely accessed, reused, modified and shared by anyone" (Downes, 2011). Open educational resources are still in the early adoption stage; the genesis of OER was the open source computing movement (Brown \& Adler, 2008) and its first application to learning was "learning objects." Wiley tackled the definition of learning objects in 2000 and offered the following: "any digital resource that can be reused to support learning" (2000, p. 4). Compare this to Downes' 2011 definition of open educational resources above and indeed they have similarities: Wiley (2000) suggested the critical attributes of learning objects are "reusable", "digital", and "resource". Downes (2011) included these attributes in his definition of OER - although digital is not mentioned it could be construed as implied in this digital age. Thus the term "learning object" could be considered a formative definition preceding OER.

Types of OER include lessons, modules, full courses/programmes, guides, e-texts, articles, audio tracks, videos, multimedia, and any other learning materials (UNESCO \& Commonwealth of Learning, 2011; Hylen, 2007). One of the main purposes for OER is to support education; they do so with heightened accessibility and they have the potential to reduce barriers to learning through enhanced attention, motivation, and engagement of students (Sclater, 2010).

Open textbooks are one type of OER initiative that has gained attention recently with several governments, such as the state of Washington (Overland, 2011) and the state of California (Volmer, 2012), investing millions of dollars in the development of these resources for use by community college students. The province of British Columbia has also announced funding for 40 open textbooks (Government of BC, 2012). These bold actions can reduce the financial barriers to education for many; a recent report from the center for Public Interest Research found that using open textbooks could reduce student costs by $80 \%$ (Allen \& PIRG, 2010).

The above examples of policy changes at the government level may minimize some of the barriers to adopting OER, but several more exist. Nie (2012) noted multimedia skills, knowledge of copyright law and licensing practices, and search ability as barriers. There are many good repositories but not knowing where to look constitutes a barrier for time-challenged faculty and staff. As the OER movement is worldwide there are cultural differences as well (Nie, 2012). Murphy (2012) notes time, organizational culture, and availability of resources as being significant barriers. De Liddo (2010) confirms this higher education cultural barrier of "opening up" and suggests technology aimed at connecting and collaborating could minimize this. One of the main issues that inhibits sharing and openness in higher education is intellectual property. Organizations such as Creative Commons preserve the rights of the authors by providing a variety of licences that allow them to choose the conditions for sharing their work. Their mission is to "develop, support and steward legal and technical 
infrastructure that maximizes digital creativity, sharing and innovation" (creativecommons.org/about).

Downes (2007) noted that OER production is largely voluntary and motivation is altruistic. He pointed to two human characteristics of the community OER approach: Human interaction is needed to build OER; and the users of OER must be respected (Foote as cited in Downes, 2007). Pawlowski (2012) suggested that one factor which could further the adoption of OER is increased emotional ownership, defined as "the degree that individuals perceive that knowledge or resources belong to them" (Clements \& Pawlowski, 2012). While this view could be seen as antithetical to the community OER approach outlined by Downes (2007), in fact, because of altruistic motivation for creating OER, emotional ownership strengthens the community. Emotional ownership, in concert with organizations such as Creative Commons, could also contribute to opening up the private practice of teaching and scholarship in higher education institutions. Pawlowski (2012) outlined a four-phase collaborative development cycle for OER:

Design \& Develop $\Rightarrow$ Redesign $\Rightarrow$ Reuse $\Rightarrow$ Republish

In this cycle, emotional ownership can increase as reuse and republishing occur in their respective communities (Pawlowski, 2012). Pawlowski concluded that OER collaborators must be encouraged, engaged, and supported throughout the OER development process (Pawlowski, 2012).

The key issue this research project addressed was measuring the health of the Athabasca University OER collaborative development cycle. Using OER is an indicator of adoption, but creating OER and adding back to the community are key to broader adoption and sustainability, both within the community and beyond.

Our goal was to determine how our institution is adopting OER so that insights could be made about how to further adopt, develop policy, and recognize the commitment of our community. Surveys have been created recently such as Murphy (2012), Open Access Textbook Project (2010), Petrides et al. (2010), The OER Impact study (White \& Manton, 2011), and the UK-OER Synthesis and Evaluation Project (McGill et al., 2013) to measure key factors in OER adoption, and our survey is designed to be a reusable instrument which can be easily administered to determine OER adoption progress. Our survey is different from Murphy's (2012) benchmark study, which has a considerable policy focus. While our pilot was offered specifically at an open university, our intention was to provide a valuable tool to measure the use and creation of OER in any institution.

This research focused on the following questions:

- Are faculty and staff in the sample using OER?

- What type of OER have faculty used? 
- What factors could facilitate using OER?

- Are faculty and staff creating OER?

- What type of OER are faculty and staff creating?

- What factors could facilitate creating OER?

\section{Method}

To answer the above research questions, a quantitative survey was developed to measure the use of, creation of, and attitudes toward OER in our institution. The survey was based on the Open Access Textbook Task Force Final Report (OATTFF) (2010) and adapted with permission (I. Cook, personal communication, October 23 ${ }^{\text {rd }}$, 2011). The data collected in the survey were used to fulfill Florida Statute 1004.091 (2), which provided a legislative mandate to research key factors of a publicly funded open textbook model (Open Access Textbook Taskforce, 2010). Now with a new name, the Florida Virtual Campus has emerged to be a leader in the field and is helping other states adopt open textbooks based on their findings (Florida Virtual Campus, 2012). The survey questions were well designed to measure the use of, creation of, and attitudes toward using open textbooks, a specific type of OER. To expand the breadth of the survey and create a valuable tool to measure adoption of OER, we added questions to ascertain what type of OER were being used or created, and other refinements were made to obtain information that would help clarify the state of adoption of OER in general. A conditional question was included in the Use section of the survey: If the participant answered "no" to the OER Use question they were taken directly to the Attitude section of the survey. A copy of the OER Readiness Survey tool is available from Athabasca University's digital repository AU Space.

The sample was composed of academic, professional, and administrative staff at Athabasca University. Thirty-four percent were faculty and $14 \%$ were tutors, while $11 \%$ were members of a course development team. Two percent identified themselves as administrators. Areas of responsibility were quite evenly split between general studies (39\%), upper division courses (32\%), and graduate courses (31\%). The survey was anonymous and open to all staff. The all staff email also served as part of an awarenessraising strategy.

The total number of AU staff and faculty who could have seen the invitation to complete the survey was approximately 1,300. The respondent sample size was 154 responses with 90 complete responses. This is a very low response rate, however it is unlikely that administrative staff with no connection to course development or delivery would have responded. The number of faculty and course development staff is approximately 200. It's difficult to calculate a margin of sampling error. 
Both complete and incomplete responses were included in the analysis because the incomplete responses could have been a result of question design. For example, not applicable was not an option on some of the questions and it was possible that respondents did not have enough information or knowledge to answer the questions completely. Using incomplete responses also allowed us to determine how much awareness there was among staff at the time of the survey, and to infer where there were gaps in knowledge about OER.

In the presentation of findings below, the sample size is noted for each result. Data were collected for 10 days and did not include any incentive. There was one reminder a week after the initial invitation. There were 22 questions in the anonymous survey and all questions were non-mandatory. Downe's definition of OER (2011) was used in the invitation to participate as well as in the survey when asking about use and creation of OER.

\section{Description of the Sample}

Table 1

Position Summary, $\mathrm{N}=105$

Role Count $\quad \%$

Full time faculty member $53 \quad 34$

$\begin{array}{lll}\text { Tutor } & 22 & 14\end{array}$

$\begin{array}{lll}\text { Member of course } & 11 & 7\end{array}$

development team $\quad 11$

Production staff member 44

Administrator

$4-2$

Table 2

Familiarity with $\mathrm{OER}, \mathrm{N}=109$

$\begin{array}{lll}\text { Answer } & \text { Count } & \% \\ \text { Somewhat familiar } & 65 & 59 \\ \text { Very familiar } & 25 & 22 \\ \text { Not at all familiar } & 11 & 10 \\ \text { No answer } & 8 & 7\end{array}$




\section{Results}

\section{Research Question 1: Are Faculty And Staff Using OER?}

Table 3

OER Use in Courses, $\mathrm{N}=109$

$\begin{array}{lll}\text { Answer } & \text { Count } & \% \\ \text { Yes } & 45 & 41 \\ \text { No } & 41 & 37 \\ \text { No answer } & 23 & 21\end{array}$

\section{Research Question 2: What OER Are Faculty and Staff Using?}

The survey asked participants how likely they were to use 13 different types of OER. The sample size for this question was 90. When "Very Likely and "Somewhat Likely" responses were added together to indicate inclination, the following OER were revealed to be strong candidates in terms of use.

Table 4

Types of OER Used, $\mathrm{N}=90$

$\begin{array}{lll}\text { Type of OER } & \text { Combined \% } & \text { Count } \\ \text { Scholarly journal access } & 72 & 65 \\ \text { Video } & 68 & 62 \\ \text { Images } & 65 & 59 \\ \text { Textbooks } & 65 & 59 \\ \text { Audio } & 62 & 56\end{array}$

\section{Research Question 3: What Factors Would Increase Use of OER?}

The survey asked participants how important nine different factors were to use OER. The sample size for this question was 90. When "Very Likely and "Somewhat Likely" responses were added together to indicate inclination, the results are as follows (most important to least important). 
Table 5

Factors to Increase Use of OER, N $=90$

Factor

Combined \%

Count

Academic quality

87

78

Time to find, review, select $\quad 82$

74

Knowledge about OER

78

70

Desire to reduce costs for

students

74

67

Hardware / software to

74

67

facilitate use

Environmental concerns

68

61

Support from

67

60

administration

Course team support

66

59

Recognition

57

51

\section{Research Question 4: Are Faculty and Staff Creating OER?}

Table 6

OER Creation by Faculty and Staff, N = 154

$\begin{array}{lll}\text { Answer } & \text { Count } & \% \\ \text { Yes } & 44 & 29 \\ \text { No } & 110 & 72\end{array}$

\section{Research Question 5: What Types of OER Are Faculty Creating?}

The survey asked participants if they were creating any of 13 different types of OER. The sample size for this question was 90. When "Very Likely and "Somewhat Likely" responses were added together to indicate inclination, the following OER were the most popular resources being created. 
Table 7

Types of OER Being Created, N =90

$\begin{array}{lll}\text { Type } & \text { Count } & \% \\ \text { Tutorials } & 21 & 23 \\ \text { Quiz } & 17 & 19 \\ \text { Audio } & 14 & 16 \\ \text { Video } & 14 & 16 \\ \text { Images } & 13 & 14 \\ \text { Group of lessons } & 13 & 14 \\ \text { Textbooks } & 10 & 11 \\ \text { Scenarios case studies } & 9 & 10 \\ \text { Software } & 8 & 8 \\ \text { Other } & 8 & 8 \\ \text { Game } & 7 & 7 \\ \text { Animation } & 6 & 7 \\ \text { Maps } & 4 & 4\end{array}$

\section{Research Question 6: What Factors Would Increase Creation of OER?}

Table 8

Factors to Increase Creation of $\mathrm{OER}, \mathrm{N}=70$

$\begin{array}{lll}\text { Factor } & \text { Combined \% } & \text { Count } \\ \text { Academic quality } & 74 & 67 \\ \text { Course team support } & 73 & 66 \\ \text { Knowledge about OER } & 72 & 65 \\ \text { Hardware/software } & 72 & 65 \\ \text { Support from } & 71 & 64 \\ \text { administration } & & \\ \text { Time to review/ select } & 71 & 64 \\ \text { Desire to reduce costs to } & 67 & 60 \\ \text { students } & & 60 \\ \text { Environmental concerns } & 67 & 57 \\ \text { Recognition } & 63 & \end{array}$

\section{Discussion}

Murphy (2012) noted that there is value in benchmarking, and the survey created for this research could serve as a standardized tool to collect benchmarking data about OER in any educational institution. While the survey could be further adapted to meet an institution's specific needs, there is value in a standard measurement tool. The samples in Murphy's study were from participating members of the recently launched OER 
University; Athabasca University is one of the charter member universities. Together, a top-line benchmark could be drawn. In this sample, the vast majority of the participants knew about OER: $82 \%$ were either very familiar or somewhat familiar. The familiarity level might not be as high if a similar survey were to be given at another institution that was not focused on openness, but the data from a standard measurement tool could still be compared and contrasted.

The OER Readiness Survey could also be used as an awareness tool. The survey findings were shared with two different groups in spring of 2013 and each presentation generated significant discussion among those who attended. In addition to generating OER awareness, the OER Readiness Survey can be used to identify learning needs; the final questions in the survey ask for respondents' interest in learning about six key areas in OER and how they would like to learn more about these topics.

It is interesting to note that despite the recent government support of open textbooks as described above, textbooks were fourth on the list in terms of being used and seventh in terms of OER being created. These numbers will likely change as policies and procedures are put in place from the legislative level. Overall, the use and creation results are encouraging: $41 \%$ of the sample indicated they use OER while $37 \%$ create OER. There is still some progress to be made in terms of use and creation but we do have an indication of what factors would increase these measures.

There is some overlap in the factors for both using and creating OER as displayed in Figure 1.

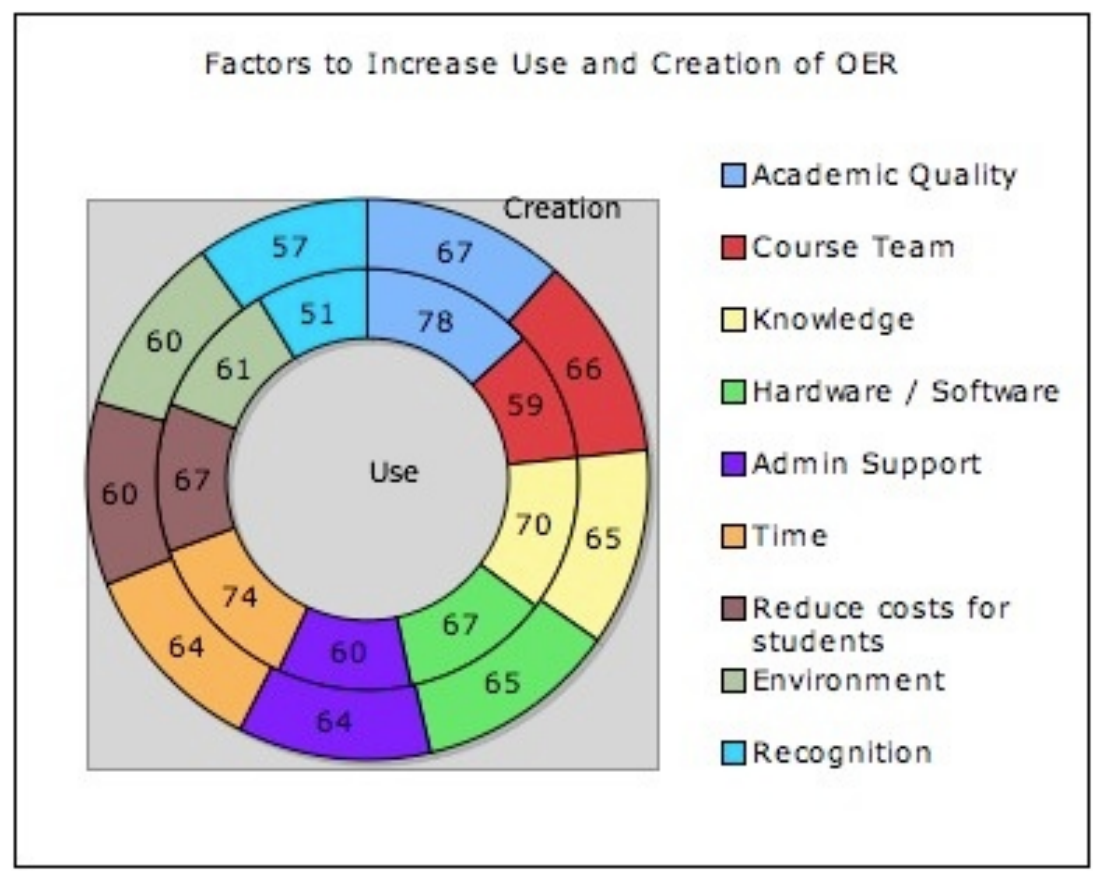

Figure 1. Factors to increase use and creation of OER. 
The numbers above are the counts from Table 5 (factors to increase use - inside circle) and Table 8 (factors to increase creation of OER - outside circle). Surprisingly, recognition is the lowest factor for both OER creation and use factors. This could suggest that intrinsic motivation drives faculty and staff who use and create OER. It could also suggest that AU faculty aren't used to recognition so don't expect it and aren't driven by recognition. This interpretation may still be evidence of intrinsic motivation.

This evidence of intrinsic motivation aligns with Pawlowski's emotional ownership model (2012) of OER creation and use. Academic quality is the highest factor for both use and creation and this also has to do with emotional investment. The participants were all involved in designing learning, and they want their students to succeed. Knowledge of OER is also high on the list for both creation and use. This could be because in the higher education environment, there is an intrinsic component to acquiring new knowledge.

Daniel (2011) described OER work as "patchy". He wrote that until the focus of OER is on "production" instead of "reuse" it could not be considered a mainstream adoption (Daniel, 2011). Therefore, a ratio of use to creation could be a useful metric to measure adoption of OER. Downes (2006), Daniel (2011), and Pawlowski (2012) all emphasize the importance of creating as well as using OER. The OER adoption ratio for this research project would be 39 (use) to 28 (creation) based on a sample of 90 complete responses. Presented as percentages of the total sample, the ratio would be 43:31. Further research could be done to determine what exactly is the best ratio. Is it when both are equal? Is a ratio an accurate representation of adoption? This notion could be further developed after more institutions use the survey tool to obtain OER adoption data.

Possible limitations to the study include self selection: Faculty and staff at Athabasca University could be naturally interested in OER and feel confident in their knowledge in this area and may be early adopters of educational innovations. There could also be possible differences between the groups represented in the sample resulting in overlapping data if a team selects course resources. For example, if a course developer and tutor were both involved in the decision, both would report that they use OER. As noted above, $2 \%$ of the sample - or four people - identified themselves as administrators such as chair, coordinator, dean, or other. In any higher education institution, decision makers exist at all levels, and faculty especially contribute to policy, procedure, and practice decisions. In the collegial context that is one of the hallmarks of universities, consultation with stakeholders is a critical component of any strategic planning initiative for change. Finding out what users/creators of OER (faculty, designers, etc.) need in order to make their use/creation successful is an essential part of managing the course development process. Finally, OER are digital by nature and digitally literate respondents might be more inclined to answer the survey questions, indicating an overrepresentation on the use and creation side. While these are limitations, they do not negate the value of having identified the benchmark. 
A large amount of data was collected with this survey; in the interest of focus we decided to concentrate on descriptive statistics of use and creation of OER. Further research could explore the data in greater detail and correlation could reveal further salient results. To track progression in adopting OER and identify trends it would be valuable to re-offer the survey at regular intervals. As there are many stakeholders in OER adoption such as decision makers and students (White \& Manton, 2011) a “360" type of survey might make the results multi-dimensional.

\section{Conclusion}

At Athabasca University, OER are being both used and created and the motivation for both seems largely intrinsic. The data collected from the OER Readiness Survey tool concurs with Pawslowski (2012) that creating OER leads to higher emotional engagement than simply using OER. If use and creation do add emotional ownership and reduce a barrier of non-attachment to shared resources, then a ratio of use:creation could be useful for measuring OER adoption at an institution. The small gap between OER use and OER creation could be a possible indicator of healthy adoption of OER.

Because of the intrinsic nature of using and creating OER, institutional policy on OER should focus on encouragement, engagement, and support throughout the OER process (Pawslowski, 2012). This means implementing a pro-OER policy making use of available OER whenever possible, conducting searches for OER before considering commercial resources, and supporting a pro-OER environment within the institution. Further, it could mean changing the perspective of course development teams from course building to course assembly, thereby including course assembly as part of the "creative" course development process.

This tool was piloted at Athabasca University and the authors' intentions were to provide a useful tool to further the adoption of OER at other institutions. They could use the survey tool developed for this research so that use and creation of OER can be measured and benchmarks identified. After time and effort are invested in training staff and faculty how to find, evaluate, adapt, and integrate OER in their course development projects, the survey could be offered again to determine if there are increases in awareness, use, and creation and differences in the relationships among factors affecting use and creation. The survey tool and related data will contribute to consistent adoption of OER in the higher education community and students, teachers, and society, as a whole, will benefit. 


\section{References}

Allen, N., \&PIRG, S. (2010). A cover to cover solution: How open textbooks are the path to textbook affordability. Student PIRGs.

Brown, J . S., \& Adler, R. P. (2008). Open education, the long tail, and learning 2.0. Educause Review, 43(1), 16-20.

Clements, K. I., \& Pawlowski, J . M. (2012). User-oriented quality for OER: Understanding teachers' views on re-use, quality, and trust. J ournal of Computer Assisted Learning, 28, 14-14.

Daniel, J . (2011, May 9th). Open educational resources (OER): Switching focus from production to re-use? [Weblog comment]. Retrieved from http:// www.col.org/blog/ Lists/Posts/ Post.aspx?ID=140

De Liddo, A. (2010). From open content to open thinking. In World Conference on Educational Multimedia, Hypermedia and Telecommunications (Ed-Media 2010). Toronto, Canada.

Downes, S. (2011, J uly 14th). Open educational resources: A definition [Weblog comment]. Retrieved from http:// halfanhour.blogspot.com/2011/ 07/ openeducational-resources-definition.html

Downes, S. (2006). Models for sustainable open educational resources. National Research Council Canada. Retrieved from http:// www.oecd.org/document/32/0,2340,en_2649 $33723 \quad 36224352 \quad 1 \quad 1$ 1 1,00.html

Downes, S. (2007). Models for sustainable open educational resources. Interdisciplinary J ournal of Knowledge and Learning Objects, 3, 29-44. Retrieved from ijello.org/ Volume3/ IJ KLOv3p029-044Downes.pdf

Government of British Columbia. (2012). BC to lead Canada in offering students free, open textbooks [Press Release]. Retrieved from http://www2.news.gov.bc.ca/news_releases_2009-2013/2012AEIT0010$\underline{001581 . h t m}$

Hylen, J . (2007). Giving knowledge for free: The emergence of open educational resources. Retrieved from http:// www.oecd.org/ dataoecd/35/ 7/38654317.pdf

McGill, L., Falconer, I., Littlejohn, A., \& Beetham, H. (2013, February). J ISC/ HE Academy OER Programme: Phase 3 synthesis and evaluation report. J ISC. Retrieved from https:// oersynth.pbworks.com/w/ page/ 59707964/ukoer3FinalSynthesisReport 
Murphy, A. (2012). Benchmarking OER use and assessment in higher education. University of Southern Queensland, Toowoomba, Australia.

Nie, M. (2012). EVOL-OER: The evolution of OER. SCORE Fellowship final report. University of Leicester, Leicester, UK.

Overland, M. (2011, J anuary 9). State of Washington to offer online materials as texts. Chronicle of Higher Education. Retrieved from http:// chronicle.com/article/ State-of-Washington-to-Offer/ $125887 /$

Open Access Textbook Task Force. (2010). Final report. State of Florida, Tallahassee, USA.

Pawlowski, J . M. (2012, September). Emotional ownership as the key to OER adoption: From sharing products and resources to sharing ideas and commitment across borders. EFQUEL Innovation Forum.

Petrides, L., Jimes, C., Middleton-Detzner, C., \&Howell, H. (2010). OER as a model for enhanced teaching and learning. In Open Ed 2010 Proceedings. Barcelona: UOC, OU, BYU. Retrieved from http:// hdl.handle.net/ 10609/4995

Sclater, N. (2010). Open educational resources: Motivations, logistics and sustainability. In N. F. Ferrer \&J . M. Alonso (Eds.), Content management for e-learning. Retrieved from http://sclater.com/ papers/OER-Motivations-Logistics-andSustainability-Sclater.pdf

Volmer, T. (2012, September 27). California passes groundbreaking open textbook legislation [Weblog comment]. Retrieved from http:// creativecommons.org/tag//california

UNESCO, Commonwealth of Learning. (2011). Guidelines for open educational resources (OER) in higher education. Retrieved from http:// www.col.org/resources/publications/Pages/detail.aspx?PID=364

White, D., \& Manton, M. (2011). J ISC-funded OER impact study. University of Oxford.

Wiley, D. A. (2000). Connecting learning objects to instructional design theory: A definition, a metaphor, and taxonomy. In D. A. Wiley (Ed.), Learning technology. Association for Instructional Technology \& Association for Educational Communications and Technology. Retrieved from http:// reusability.org/read/ chapters/ wiley.doc 


\section{Athabasca University $\mathbf{A}$}

(c) 